\title{
Two New Improved Methods for Determination of Cobb's Angle of Scoliosis
}

\author{
Dr. med. Dietrich W. Hellen
}

arte Gesundheitszentrum
Prof. Dr. rer. nat. Michael Teusner

Fachhochschule Südwestfalen

teusner@fh-swf.de

\begin{abstract}
Cobb's traditional method for measuring the angle of scoliosis is complicated and error-prone in application. Angles measured with this method are inaccurate and it therefore stands to reason to search for improved procedures.

We propose Cobb's angle to be determined by two novel methods: the distance method and the two-angle method. Using mathematical error analysis and experimental test measurings we demonstrate that the two proposed methods offer significant advantages over the current standard. They simplify the measurement process and increase outcome accuracy.

For Cobb's angles larger than 30 degrees, the two-angle method reduces the error-variation by approx. 25\%. For Cobb's angles below 30 degrees the distance method reduces the errorvariation by approx. $50 \%$.
\end{abstract}

\section{Introduction}

Cobb's angle [1] is the fundamental measuring parameter for determining the degree of curvature in scoliosis. For determination of Cobb's angle, two straight tangent lines along the end plates of the end vertebrae of the curvature are needed. Generally, Cobb's angle $\alpha$ is measured at the point of intersection between two perpendicular lines drawn at these tangent lines (see Figure 1). However, application of this traditional procedure results in a considerable variation of error [2-10]. For small angles (mostly associated with static scoliosis) this variation of error can even reach the size of the angle itself. Thus, the measured NOTE: This preprint repgrts new research that has not been certified by peer review and should not pe used to guide clinical practice. angles can be totally wrong and the need for improved procedures is obvious. 
medRxiv preprint doi: https://doi.org/10.1101/2020.06.11.20124735; this version posted June 16, 2020. The copyright holder for this preprint (which was not certified by peer review) is the author/funder, who has granted medRxiv a license to display the preprint in perpetuity.

\section{Methods}

\subsection{Description of the Methods}

In all imaging methods for the determination of Cobb's angle, first the two tangent lines need to be established at the end plates of the inferior and superior end vertebrae (see Figure 1).

Therefore, the first two steps can be described for all methods as follows:

Step 1: Drawing the tangent line to the superior end plate of the superior end vertebra.

Step 2: $\quad$ Drawing the tangent line to the inferior end plate of the inferior end vertebra.

The various procedures differ in the following steps 3 to 5 . These differing steps are described below (see Figure 1).

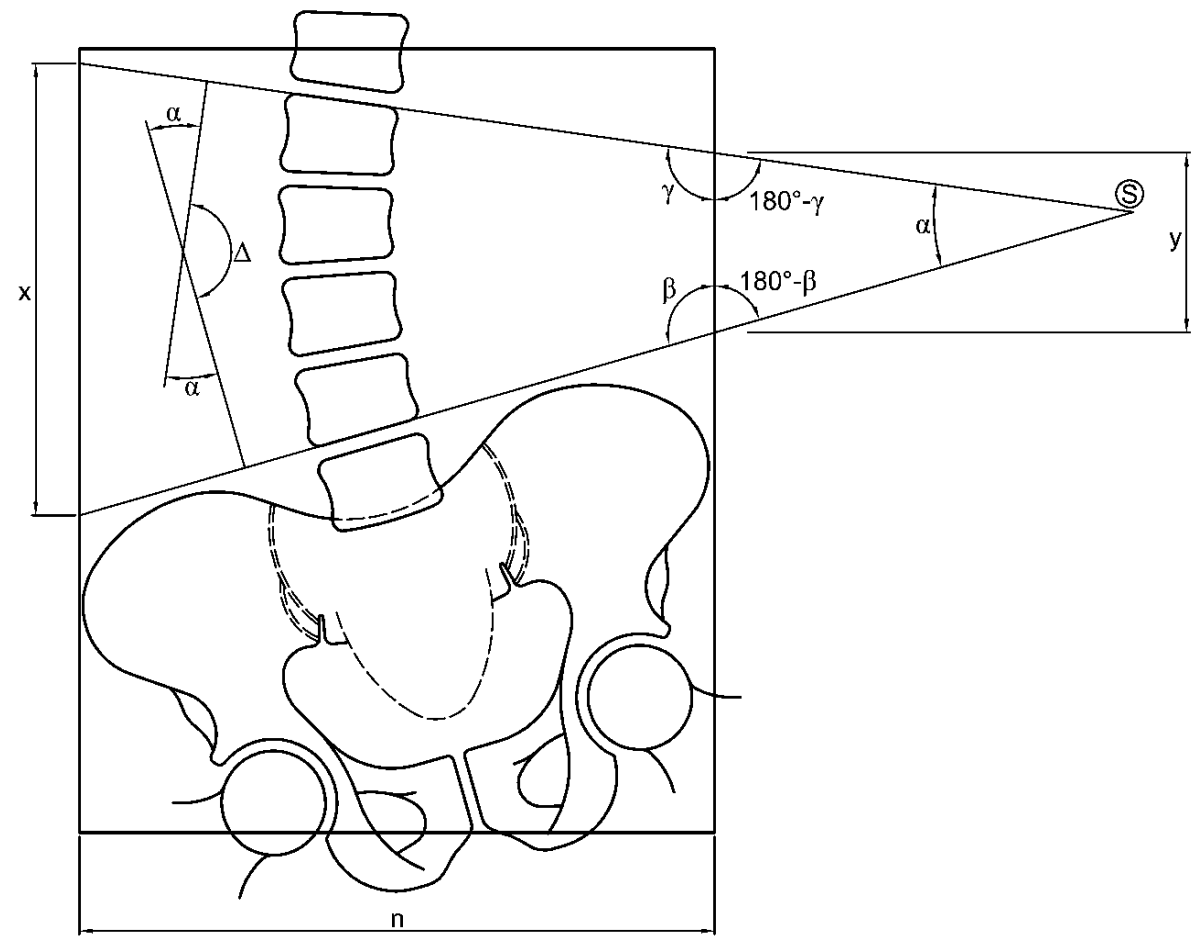

Fig 1 Measuring data for the different calculation methods 
medRxiv preprint doi: https://doi.org/10.1101/2020.06.11.20124735; this version posted June 16, 2020. The copyright holder for this preprint (which was not certified by peer review) is the author/funder, who has granted medRxiv a license to display the preprint in perpetuity.

All rights reserved. No reuse allowed without permission.

\subsubsection{Standard Cobb Method (Four-Line Method)}

Step 3: $\quad$ Drawing a perpendicular line to the superior tangent line on the radiograph next to the image of the spine.

Step 4: Drawing a perpendicular line to the inferior tangent line on the radiograph next to the image of the spine in such a way that it intersects with the upper perpendicular line.

Step 5: $\quad$ Reading Cobb's angle $\alpha$ from a protractor at the point of intersection of the two perpendicular lines.

\subsubsection{Two-Angle Method}

Step 3: $\quad$ Measuring the angle $\beta$ between the inferior tangent line and the side edge of the radiograph.

Step 4: $\quad$ Measuring the angle $\gamma$ between the superior tangent line and the side edge of the radiograph.

Step 5: $\quad$ Computing of Cobb's angle $\alpha$ by using:

$$
\alpha=\beta+\gamma-180^{\circ}
$$

\section{(Formula 1).}

\subsubsection{Distance Method}

Step 3: $\quad$ Measuring (with a ruler) the distances $x$ and $y$ between the points of intersection of the tangent lines with the side edges of the radiograph.

Step 4: $\quad$ Computing the difference $d=x-y$.

Step 5: $\quad$ Computing Cobb's angle $\alpha$ by using:

$$
\begin{array}{ll}
\alpha=\boldsymbol{d} \cdot \boldsymbol{H}_{n} & (\text { Formula 2) } \\
\text { with } \quad \boldsymbol{H}_{n}=\frac{54^{\circ}}{n} & (\text { Formula 3). }
\end{array}
$$




\subsection{Explanation of the Methods}

\subsubsection{Standard Cobb Method (Four-Line Method)}

For the angle $\alpha_{s}$ at the point $\mathrm{S}$ of intersection in Figure 1 we have:

$\alpha_{s}=360^{\circ}-2 \cdot 90^{\circ}-\Delta$

At the same time, the angle $\Delta$ at the point of intersection of the lines perpendicular to the tangent lines satisfies the equation:

$\alpha+\Delta=180^{\circ}$, so that $\Delta=180^{\circ}-\alpha$.

By introducing this term into the equation for $\alpha_{s}$ we obtain

$\alpha_{s}=360^{\circ}-2 \cdot 90^{\circ}-\left(180^{\circ}-\alpha\right)=\alpha$.

Hence the angle $\alpha$ at the point of intersection of the lines perpendicular to the tangent lines is identical to Cobb's angle $\alpha_{s}$ at the point $\mathrm{S}$ of intersection of the tangent lines.

\subsubsection{Two-Angle Method}

Cobb's angle $\alpha$ can be determined without the construction of perpendicular lines to the tangent lines (as necessary in the Cobb Method). For this purpose one must determine the angles $\beta$ and $\gamma$ at which the tangent lines meet the side edge of the radiograph. With these angles, the sum of the angles in the triangle outside the radiograph (see Figure 1) satisfies the following equation:

$\left(180^{\circ}-\beta\right)+\left(180^{\circ}-\gamma\right)+\alpha=180^{\circ}$.

Thus we have:

$\alpha=\beta+\gamma-\mathbf{1 8 0}^{\circ}$

(Formula 1).

This equation is valid for all film formats and all angles of curvature of scoliosis, if the tangent lines intersection point S lies outside of the radiograph. Should the tangent lines intersect on the radiograph, Cobb's angle $\alpha$ can be read directly at point S. 
medRxiv preprint doi: https://doi.org/10.1101/2020.06.11.20124735; this version posted June 16, 2020. The copyright holder for this preprint (which was not certified by peer review) is the author/funder, who has granted medRxiv a license to display the preprint in perpetuity.

\subsubsection{Distance Method}

The Distance Method allows determination of Cobb's angle without using a protractor. For the description of this simple procedure we refer to Figure 2.

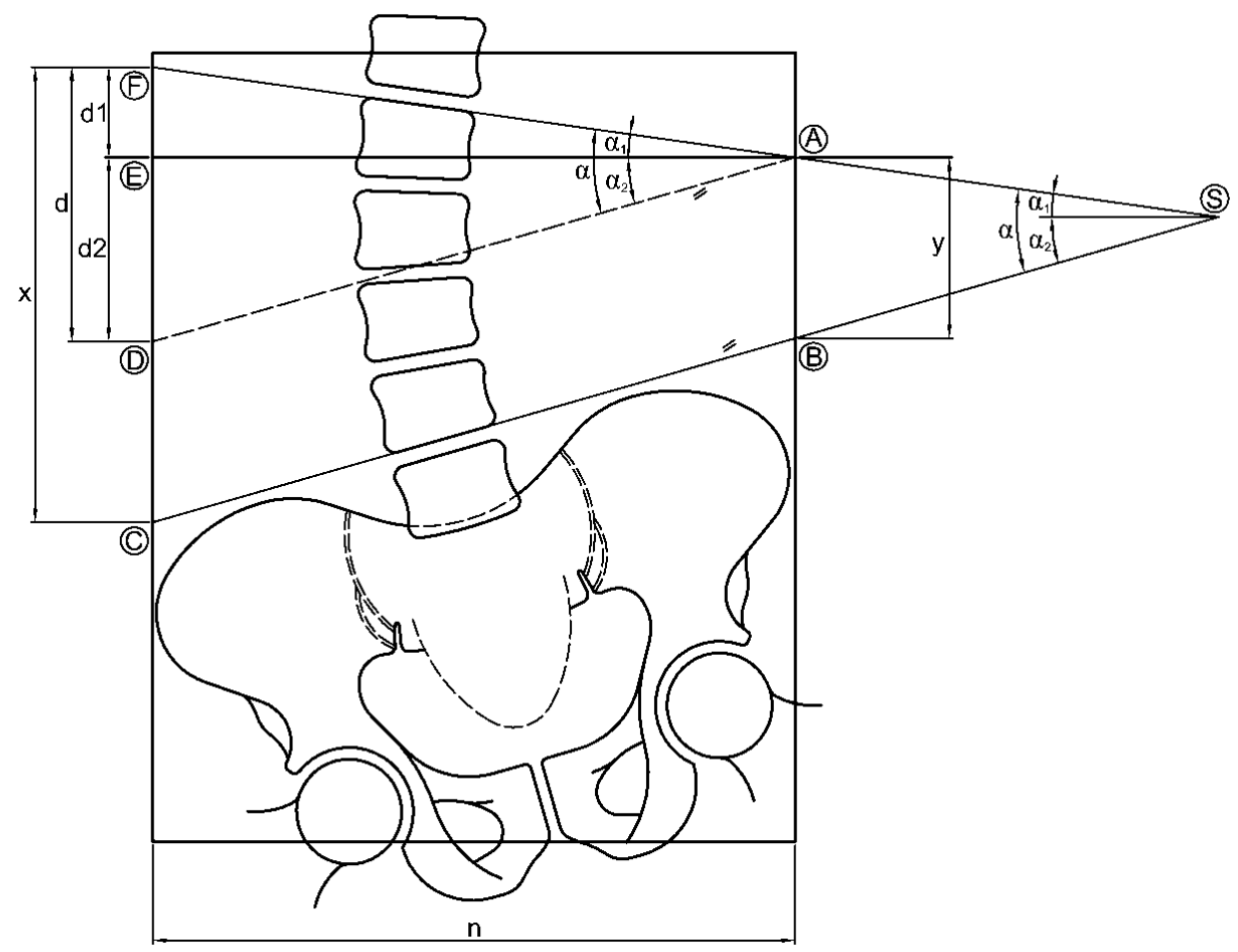

Fig 2 Explanation of the Distance Method

Cobb's angle $\alpha$ is composed of the two partial angles $\alpha_{1}$ and $\alpha_{2}$.

By parallel shifting the line segment $\mathrm{BC}$ into the line segment $\mathrm{AD}$, the angle $\alpha$ is moved (as a congruent step angle) from point $\mathrm{S}$ to point $\mathrm{A}$. The two partial angles $\alpha_{1}$ and $\alpha_{2}$ are now located in rectangular triangles, namely $\alpha_{1}$ in EAF and $\alpha_{2}$ in EAD.

The line segment EA equals the width of the radiograph $n$ so that:

$\tan \alpha_{1}=\frac{d_{1}}{n} \quad$ and $\quad \tan \alpha_{2}=\frac{d_{2}}{n}$.

Hence:

$\alpha_{1}=\arctan \frac{d_{1}}{n} \quad$ and $\quad \alpha_{2}=\arctan \frac{d_{2}}{n}$.

As $\alpha=\alpha_{1}+\alpha_{2}$, we have:

$\alpha=\arctan \frac{d_{1}}{n}+\arctan \frac{d_{2}}{n} \quad(\arctan$ Formula) 
As the accurate computation of $\alpha$ by the arctan Formula would be complex, it will not be used for the Distance Method directly. Instead of this, a simplified formula shall be applied. For small angles (up to $30^{\circ}$ ) the arctan function is almost linear. Due to this fact, as long as the fractions $\frac{d_{1}}{n}$ and $\frac{d_{2}}{n}$ in the arctan Formula are sufficiently small, the arctan function can be replaced by an appropriate linear function as follows:

$$
\arctan \frac{d_{1}}{n} \quad \text { by } \quad d_{1} \cdot H_{n} \quad \text { and } \quad \arctan \frac{d_{2}}{n} \quad \text { by } \quad d_{2} \cdot H_{n} \text {. }
$$

Here $H_{n}$ is a constant corresponding to the film width $n$.

Linearization simplifies the arctan Formula for $\alpha$ so that

$\alpha=d_{1} \cdot H_{n}+d_{2} \cdot H_{n}=\left(d_{1}+d_{2}\right) \cdot H_{n}$.

The sum of the distances $d_{1}$ and $d_{2}$ equals the distance $d$, which in turn equals the difference between $x$ and $y$. Hence

$d_{1}+d_{2}=x-y=d($ see Figure 2$)$,

with $d$ being the difference of the distances between the points of intersection of the tangent lines at the right and left side edges of the radiograph, respectively.

Thus,

$$
\boldsymbol{\alpha}=\boldsymbol{d} \cdot \boldsymbol{H}_{n}
$$

\section{(Formula 2)}

For any film width $n$ the film's characteristic parameter $H_{n}$ is defined in such a way that the tolerable error occurring in linearizing the arctan function is as small as possible. This is the case, if $H_{n}$ is calculated according to

$$
H_{n}=\frac{54^{\circ}}{n}
$$

(Formula 3).

In this formula $54^{\circ}$ is used as a constant value for each film width $n$ in order to optimize the linear approximation of the arctan function (for details see error analysis in the supplementary supporting file).

Hence, Cobb's angle $\alpha$ results as the product of the difference of the edge lengths $d$ and the film's characteristic parameter $H_{n}$, which only depends on the film width $n$. 
medRxiv preprint doi: https://doi.org/10.1101/2020.06.11.20124735; this version posted June 16, 2020. The copyright holder for this preprint (which was not certified by peer review) is the author/funder, who has granted medRxiv a license to display the preprint in perpetuity.

All rights reserved. No reuse allowed without permission.

In daily application, radiographs are usually taken with standardized film formats.

Conveniently, factor $H_{n}$ only needs to be calculated once for each film width $n$ used.

With $n=15 \mathrm{~cm}, 20 \mathrm{~cm}$ and $35 \mathrm{~cm}$ for example Formula 3 results in:

$H_{15}=\frac{3.6^{\circ}}{\mathrm{cm}}, H_{20}=\frac{2.7^{\circ}}{\mathrm{cm}} \quad$ and $H_{35}=\frac{1.54^{\circ}}{\mathrm{cm}}$.

With fixed $H_{n}$ only $d$ needs to be determined for the calculation of $\alpha$ by Formula 2 (without a protractor).

For illustration refer to Figure 1:

Here from a (true to scale) print you can take $n=7 \mathrm{~cm} \quad$ and $\quad H_{7}=\frac{54^{\circ}}{7 \mathrm{~cm}}=\frac{7.7^{\circ}}{\mathrm{cm}}$.

For the determination of $\alpha$ by the Distance Method proceed as follows:

a) Read $\quad x=5 \mathrm{~cm}$ and $y=2 \mathrm{~cm}$ resulting in $d=x-y=5 \mathrm{~cm}-2 \mathrm{~cm}=3 \mathrm{~cm}$.

b) Calculate $\quad \alpha=d \cdot H_{7}=3 \mathrm{~cm} \cdot \frac{7.7^{\circ}}{\mathrm{cm}}=23.1^{\circ}$. 


\section{Comparison of the Three Methods}

\subsection{Error Analysis}

The three methods considered here have in common that two tangent lines need to be established manually. Thus the variation of error in the determination of the tangent lines is identical for all methods. It is from the subsequent steps within each of the three different methods that different variations of error result for the whole procedures. Here the methods differ significantly in their variation of error and accuracy. In the supplementary file a detailed error analysis is given for the considered methods. As a result from this analysis we can state that with a probability of $95 \%$ the expected maximum deviation from the true angle occurring in steps 3 to 5 of the methods is limited as follows:

- Standard Cobb Method: \pm 4 degrees

- Two-Angle Method: \pm 3 degrees

- Distance Method: $\quad \pm 1.3$ degrees for angles up to $25^{\circ}$

\pm 2 degrees for angles between $25^{\circ}$ and $30^{\circ}$.

\subsection{Test Measurements}

In order to verify the different error deviations determined for the three methods by mathematical error analysis, test measurements were carried out with templates for different Cobb's angles (in all templates a width of $n=18 \mathrm{~cm}$ has been used). For this purpose 60 test persons (students) were given 6 different measuring templates each, in which the end vertebrae lines for different geometric constellations were given (Cobb's angles in the magnitudes of $5^{\circ}$, $10^{\circ}, 20^{\circ}, 30^{\circ}, 40^{\circ}$ and $50^{\circ}$ ). They were instructed to determine Cobb's angle in every template pattern by the traditional Cobb Method (Four-Line Method) and to read the angles $\beta$ and $\gamma$ for the Two-Angle Method. Additionally, the line lengths $x$ and $y$ for the Distance Method should be read for all angles up to $30^{\circ}$. With the help of the formulas given for the different methods, the corresponding Cobb's angles were then calculated on the basis of these values.

For all calculated angles, the mean values of the measurements from all three methods differed by less than $0.5^{\circ}$ (as expected).

As a measure of the distribution of the data, the standard deviation of the 60 test results for Cobb's angle was computed in each case for all procedures and every calculated angle. In the mean the three methods yielded the following standard deviations $\sigma$ of the data: 
medRxiv preprint doi: https://doi.org/10.1101/2020.06.11.20124735; this version posted June 16, 2020. The copyright holder for this preprint (which was not certified by peer review) is the author/funder, who has granted medRxiv a license to display the preprint in perpetuity.

All rights reserved. No reuse allowed without permission.

\begin{tabular}{|c|c|}
\hline Method & Standard deviation $\boldsymbol{\sigma}$ (in degree) \\
\hline Four-Line Method & 1.23 \\
\hline Two-Angle Method & 0.73 \\
\hline Distance Method & 0.30 \\
\hline
\end{tabular}

Table 1: Standard Deviations of test measurements for the different calculation methods

In normally distributed samples $99.7 \%$ of the values are within a range of $\pm 3 \sigma$ of the mean value. Therefore we can conclude from the data that the variation of error of the mean value resulting from errors of measurement in steps 3 to 5 has the following magnitude:

\begin{tabular}{|c|c|}
\hline Method & $\mathbf{3 \sigma}=\mathbf{9 9 . 7 \%}$ deviation (in degree) \\
\hline Four-Line Method & \pm 3.69 \\
\hline Two-Angle Method & \pm 2.19 \\
\hline Distance Method & \pm 0.90 \\
\hline
\end{tabular}

Table 2: Error variations of test measurements for the different calculation methods

For the recommended film width of $n=35 \mathrm{~cm}$ the standard deviation for the Distance Method (as presented in Table 1 for $n=18 \mathrm{~cm}$ ) would halve proportionally to only 0.15 degrees, whereas it would remain unaltered for the two other methods. For this the $99.7 \%$ variation of error in the Distance Method even comes to only \pm 0.45 degrees.

In their magnitude, the results of the test measurements confirm the proportion for the statistical distribution of the values obtained for the examined methods from error analysis.

\subsection{Results}

Compared to the Standard Cobb Method (Four-Line Method), the Two-Angle Method improves the variation of error for the subsequent steps 3 to 5 by at least $25 \%$. The Distance Method provides an improvement on the variation of error of at least $50 \%$, as long as Cobb's angle does not exceed 30 degrees. In this method, the improvement on the variation of error is the better the wider the film format is. Using the Distance Method with a film width of $35 \mathrm{~cm}$ would even result in an improvement of $75 \%$ for angles smaller than $25^{\circ}$. The advantage of accuracy of the Distance Method is especially evident for small Cobb's angles as here the approximation error is almost zero and only the much smaller variation of the errors of 
medRxiv preprint doi: https://doi.org/10.1101/2020.06.11.20124735; this version posted June 16, 2020. The copyright holder for this preprint (which was not certified by peer review) is the author/funder, who has granted medRxiv a license to display the preprint in perpetuity.

All rights reserved. No reuse allowed without permission.

measurement has an effect. When different Cobb angle measurements shall be compared for a patient over a time period for determination of changes in spine curvature, application of the distance method results in an additional gain of exactness. In this case the angles to be compared are of similar magnitude and the corresponding approximation errors from linearization of the arctan function are almost identical. Consequently, when subtracting these angles, the approximation error will be eliminated and the exactness of the difference will be influenced by the very small variation of measurement errors only.

Generally it can be stated, that for small angles the Distance Method has the least variation of error. Even if the approximation error resulting from linearization of the arctan function is included, it generates the best accuracy for angles up to 30 degrees. For larger angles, the TwoAngle Method provides a smaller but still significant improvement in the accuracy of the results compared to the traditional Cobb Method (Four-Line Method).

\section{Suggestions for Practical Application}

Whenever digitized imaging and calculation methods are not available and Cobb's angle needs to be determined by hand on a radiograph, we recommend using the new procedures in order to minimize the variation of error. Both methods are more accurate, simpler, faster and more reliable than the traditional Four-Line Method.

For Cobb's angles up to a magnitude of approx. 30 degrees, especially for small angles in the range between 1 and 10 degrees (e.g. in static scoliosis), the Distance Method should be preferred and for Cobb's angles of more than 30 degrees the Two-Angle Method should be used instead of the Four-Line Method. The new methods can be applied also for the determination of any other curvature of the spine (lordosis, kyphosis).

For determination of Cobb's angle in primary diagnostic of the lumbar spine (LS) we recommend using a radiograph format of $43 \mathrm{~cm} \times 35 \mathrm{~cm}$ in which the LS and the pelvis can be pictured in a single image (in an upright position ap). Compared to an additional radiograph of the pelvis, the topographic advantages of this format are that all parameters of geometry and static of the pelvis and the LS may be determined more easily, more reliably, more quickly, more graphically and more accurately at a reduced x-ray exposure and lower costs. In particular, should the need arise, the level of scoliosis may be better correlated with a leg length difference (measured as a difference in height of the femur heads). However, the new methods of measuring and calculating are principally applicable for any film format. 


\section{References}

1. Cobb, J. R.: Outline for the Study of Scoliosis in: Instructional course lectures. Am. Acad. Orthop. Surg. 261 ff. (1948).

2. Loder, R. T.; Urquhart, A.; Steen, H. u.a.: Variability in Cobb angle measurements in children with congenital scoliosis. J. Bone Joint Surg B. 1995; 77: 768 - 70.

3. Shea KG, Stevens PM, Nelson M, Smith JT, Masters KS, Yandow S.: A comparison of manual versus computer-assisted radiographic measurement. Intraobserver measurement variability for Cobb angles. Spine. 1998 Mar 1; 23(5): 551- 5.

4. Facanha-Filho, F. A.; Winter, R. B.; Lonstein, J. E. u.a.: Measurement accuracy in congenital scoliosis. J. Bone Joint Surg Am 2001; 83: 42 - 5.

5. Cheung, J.; Wever, D. J.; Veldhuizen, A. G.; u.a.: The reliability of quantitative analysis on digital images of the scoliotic spine. Eur. Spine J 2002; 11: 535 - 42.

6. Zmurko MG, Mooney JF, Podeszwa DA, Minster GJ, Mendelow MJ, Guirgues A: Inter- and intraobserver variance of Cobb angle measurements with digital radiographs. J. Surg Orthop Adv. 2003 Winter; 12 (4): $208-13$.

7. Kluba T., Schäfer J., Hahnfeldt T., Niemeyer T.: Prospective randomized comparison of radiation exposure from full spine radiographs obtained in three different techniques. Eur. Spine J. 2006 Apr 22; (Epub ahead of print).

8. Kuklo TR, Potter BK, Schroeder TM, O`Brien MF: Comparison of manual and digital measurements in adolescent idiopathic scoliosis. Spine. 2006 May 15; 31(11): 1240 - 6.

9. Wills BP, Auerbach JD, Zhu X, Caird MS, Horn BD, Flynn JM, Drummond DS, Dormans JP, Ecker ML.: Comparison of Cobb angle measurement of scoliosis radiographs with preselected end vertebrae: traditional versus digital acquisition. Spine. 2007 Jan 1; 32(1): 98 - 105.

10. Gstoettner M, Sekyra K, Walochnik N, Winter P, Wachter R, Bach CM: Inter- and intraobserver reliability assessment of the Cobb angle: manual versus digital measurement tools. Eur. Spine J. 2007 Jun 5; (Epub ahead of print). 